\title{
Kajian kinematika gerak pada jalur lokasi kecelakaan berisiko tinggi (blackspot) sebagai sumber belajar fisika di SMA
}

\author{
Widya Septyaning Virani ${ }^{1}$, Supeno ${ }^{2}$, dan B Supriadi ${ }^{3}$ \\ Pendidikan Fisika, Universitas Jember \\ J1. Kalimantan 37 Kampus Tegalboto, Jember 68I2I \\ Surat-e: ${ }^{\mathrm{I}}$ widyaseptyaningvirani@gmail.com; ${ }^{2}$ supeno.fkip@unej.ac.id; ${ }^{3}$ bambangsscmsc@gmail.com
}

Kajian fisika real life bermanfaat dalam pembelajaran fisika karena menyediakan sumber belajar kontekstual yang dekat dengan kehidupan sehari-hari. Untuk memperkaya sumber-sumber belajar kontekstual maka perlu dilakukan kajian terhadap berbagai fenomena kontekstual, salah satunya adalah kajian kinematika peristiwa kecelakaan yang terjadi di daerah blackspot. Peristiwa kecelakaan merupakan peristiwa kontekstual yang dekat dengan kehidupan seharihari dan dapat dikaji secara kinematika gerak. Untuk itu perlu dilakukan kajian kinematika gerak tentang peristiwa kecelakaan sehingga dapat digunakan untuk memperkaya rancangan sumber belajar kontekstual. Metode penelitian yang digunakan adalah deskriptif analitis. Penelitian diawali dengan pengumpulan data sekunder tentang kronologi kejadian kecelakaan yang ada di kepolisian dan beberapa surat kabar. Penelitian dilanjutkan dengan pengumpulan data di lapangan, yaitu data bentuk lintasan, jenis kendaraan yang lewat, dan kecepatan kendaraan yang melewati daerah blackspot. Data-data tersebut kemudian dianalisis menurut kajian kinematika gerak. Hasil kajian peristiwa kontekstual berupa kronologi kecelakaan dan besaran-besaran dinamis serta simulasi agar kecelakaan dapat dihindari. Hasil kajian ini diharapkan dapat dijadikan sebagai bahan acuan utama untuk mengembangkan sumber belajar kontekstual dan memberikan contoh nyata dalam pembelajaran fisika karena siswa dapat dengan mudah menaksirkan kejadian kontekstual tersebut.

Contextual physics studies are useful in physics learning. It provides a source of contextual learning that is close to everyday life. To enrich the sources of contextual learning, it is necessary to study the various contextual phenomena, one of which is the kinematics study of accidents that occurred in the police office and newspaper. An accident is contextual events that are close to everyday life and can be studied in kinematic motion. Therefore, it is necessary to study the kinematics of motion about accidents so that it can be used to enrich the concept of contextual learning resources. The research method used descriptive analytical. The research begins with the completion of secondary data about the chronology of accidents in the police and several newspapers. Further research with field data, i.e trajectory data, passing vehicle type, and vehicle speed passing through blackspot area. The data are then analyzed according to motion kinematics studies. Review results are the contextual event, the chronology of accidents, dynamic quantities, and simulations for accidents. The results of this study are expected to serve as the main reference material for the development of contextual learning resources and provide a real example in physics learning because it can estimate the contextual events.

Kata kunci: kinematics of blackspot, contextual learning resource, physics instruction

\section{Pendahuluan}

Kinematika merupakan ilmu yang mempelajari tentang gerak benda tanpa memperdulikan penyebab dari gerak benda. Kinematika gerak merupakan salah satu topik awal yang diajarkan dalam pembelajaran fisika di sekolah menengah. Cakupan materi yang diajarkan adalah beberapa konsep tentang besaran dinamis, yaitu posisi, kecepatan, dan percepatan yang disertai waktu [I]. 
Beberapa jenis gerak yang diajarkan umumnya meliputi gerak lurus beraturan, gerak lurus berubah beraturan, gerak vertikal, dan memadu gerak.

Materi pelajaran fisika tentang gerak merupakan materi yang sangat akrab dengan kehidupan sehari-hari namun pada praktek pembelajaran fisika di sekolah banyak ditemukan kesalahan konsep dan penguasaan materi yang relatif rendah. Hal ini dibuktikan oleh penelitian Narjaikaew [2] yang menyatakan bahwa terdapat beberapa miskonsepsi mengenai materi gerak. Permasalahan pembelajaran fisika di sekolah disebabkan oleh beberapa faktor, salah satu faktor yang menyebabkan kesulitan belajar fisika adalah kegiatan pembelajaran yang dialami siswa [3]. Kegiatan pembelajaran yang hanya terpaku pada ceramah guru dan buku ajar yang digunakan masih kurang dapat dicerna oleh peserta didik. Hal ini dikarenakan gaya bahasa yang terlalu rumit, permasalahan yang diangkat tidak pernah dialami atau diketahui peserta didik, gambar-gambar yang ditunjukkan kurang jelas dan cenderung masih asing bagi peserta didik[4]. Selain itu isi pelajaran fisika jarang dikaitkan dengan kenyataan kehidupan sehari-hari [5].

Jember merupakan salah satu kota yang memiliki angka kecelakaan cukup tinggi. Data dari Polres Jember menyatakan bahwa pada tahun 2016 terdapat 834 kecelakaan lalu lintas dengan 335 meninggal dunia, II luka berat, 942 luka ringan. Selain itu kabupaten Jember juga memiliki beberapa titik lokasi kecelakaan berisiko tinggi (blackspot) dimana pada lokasi tersebut sering terjadi kecelakaan lalu lintas. Salah satu lokasi blackspot berada di jalan raya Trisnogambar, Kecamatan Bangsalsari. Satuan Lalu Lintas Polres Jember telah mengidentifikasi lokasi tersebut sebagai jalur blackspot. Blackspotadalah adalah suatu titik atau area yang menunjukkan bahwa daerah tersebut merupakan daerah rawan kecelakaan. Blackspot dapat dilihat dari data kecelakaan dalam satu tahun. Black spot biasanya berkaitan dengan daerah perkotaan dimana lokasi kecelakaan dapat diidentifikasikan dengan pasti dan tetap pada suatu titik tertentu. Adapun kriteria lokasi blackspot secara umum adalah a) jumlah kecelakaan selama periode tertentu melebihi suatu nilai tertentu, b) tingkat kecelakaan atau accident rate (per kendaraan) untuk suatu periode tertentu melebihi suatu nilai tertentu, c) jumlah kecelakaan dan tingkat kecelakaan keduanya melebihi nilai tertentu, serta d) tingkat kecelakaan melebihi nilai kritis yang diturunkan dari analisis statistik.

Dari penjelasan mengenai kriteria lokasi titik kecelakaan blackspot secara umum yang digunakan untuk mengidentifikasi titik kecelakaan blackspot tidak dijelaskan bentuk jalan yang berpotensi menjadi blackspot. Bentuk jalan, baik itu jalan lurus, jalan menanjak, dan jalan yang menikung, memiliki potensi yang sama menjadi blackspot jika angka kecelakaan pada jalan tersebut melebihi nilai tertentu pada suatu periode.
Peristiwa kecelakaan lalu lintas merupakan peristiwa kontekstual yang sangat dekat dengan siswa dan dapat dikaji kinematika. Untuk itu peneliti tertarik untuk melakukan kajian peristiwa kecelakaan lalu lintas yang pernah terjadi pada blackspot di jalan raya Tisnogambar kecamatan Bangsalsari kabupaten Jember dan diharapkan hasil kajian ini dapat dimanfaatkan oleh guru dalam membuat rancangan sumber belajar kontekstual untuk mendukung proses pembelajaran fisika yang berkualitas.

\section{Metode Penelitian}

Jenis penelitian ini adalah penelitian deskriptif analitis. Metode deskripstif analitis merupakan metode yang bertujuan untuk mendeskripsikan atau memberi gambaran melalui sampel atau data yang telah terkumpul dan membuat kesimpulan yang berlaku umum. Alur penelitian ini dimulai dari tahap persiapan berupa pengumpulan data-data dan informasi yang mendukung penelitian beserta teori-teori yang mendasari penelitian. Data tersebut berupa data primer dan data sekunder.

Data primer berupa data hasil observasi langsung di lapangan berdasarkan literatur berupa kecelakaan pada jalur blackspot kemudian digambarkan sketsa kronologinya, sedangkan data sekunder berupa data pendukung yang diperoleh dari media massa, data dinas marga kabupaten Jember, data dari kepolisian, dan aplikasi google earth pada personal computer (PC). Selanjutnya peneliti melakukan observasi lapangan berupa pengamatan langsung untuk memperoleh data yang diperlukan dalam penelitian, yaitu kondisi jalan, kecepatan berbagai jenis kendaraan, posisi kendaraan yang terlihat kecelakaan. Setelah data dari observasi lapangan diperoleh, maka data tersebut dianalisis yang kemudian dikaji kinematika geraknya. Hasil analisis kinematika gerak tersebut dapat dijadikan sumber utama dalam menyusun rancangan sumber belajar kontekstual berupa buku ajar.

Meskipun setiap kendaraan baik kendaraan ringan hingga kendaraan berat memiliki potensi yang sama, yaitu dapat mengalami kecelakaan pada jalur tersebut namun pemilihan kendaraan tiap jalur dilakukan pada kendaraan yang berbeda-beda. Hal tersebut dipilih berdasarkan intensitas terjadinya kecelakaan pada jalur tersebut. Kendaraan yang dipilih adalah jenis kendaraan dengan intensitas terjadinya kecelakaan pada jalur blackspot tersebut adalah tinggi. Dengan menganggap kecepatan pada setiap kendaraan adalah konstan, sehingga diperoleh data $V_{0}$ untuk jarak tempuh kendaraan yang telah ditentukan oleh peneliti dibagi dengan waktu tempuh kendaraan. 


$$
v_{0}=\frac{s}{\Delta t}=\frac{100 \mathrm{~m}}{t_{2}-t_{1}} \mathrm{~m} / \mathrm{s}
$$

Berdasarkan observasi di lapangan diperoleh beberapa data nilai kecepatan kendaraan, dimana terdapat nilai maksimum yang diperoleh pada tabel vo yang dianggap sebagai batas kecepatan maksimum kendaraan melintas di jalan tersebut dan nilai minimum yang diperoleh pada tabel $v_{0}$ adalah batas kecepatan minimum kendaraan melintas di jalan tersebut. Spesifikasi tiap kendaraan juga diperlukan sebagai data pendukung guna mengetahui kecepatan maksimum dan minimum kendaraan, serta waktu yang diperlukan dan berapa jarak yang diperlukan jika terjadi pengereman mendadak. Data yang diperoleh selanjutnya digunakan sebagai dasar untuk menganalisis kecelakaan di jalur blackspot yang dimaksud.

\section{Hasil Penelitian dan Pembahasan}

Kajian kinematika dilakukan berdasarkan hasil penelitian langsung di lapangan dan data dari beberapa sumber informasi. Sumber informasi utama adalah artikel dari media massa yang menyatakan bahwa terjadi kecelakaan di jalur blackspot di kabupaten Jember serta data tersebut telah dikonfirmasi dengan informasi dari kepolisian. Kronologi kecelakaan yang terjadi pada jalur blackspot di jalan raya Trisnogambar, kecamatan Bangsalsari kabupaten Jember dapat di lihat pada sketsa kronologi kecelakaan pada Gambar I.

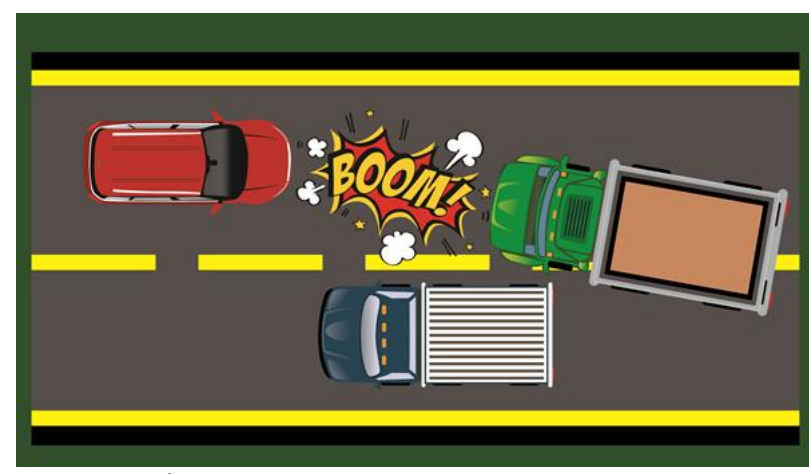

Gambar I. Kronologi kecelakaan di jalan raya

Trisnogambar kecamatan Bangsalsari kabupaten Jember

Kecelakaan bermula saat kendaraan minibus melaju dari arah barat dengan kecepatan tinggi dan pada saat yang bersamaan muncul sebuah dump truck dari arah berlawanan menyalip sebuah mobil boks. Saat truk itu kehilangan kendali, kecelakaan tidak bisa dihindarkan. Mobil minibus berusaha menghindari dump truck namun justru menghantam sisi kiri truk box. Akibat kerasnya benturan, bagian depan mobil minibus rusak parah. Jika hal ini dianalisis secara fisika dengan tinjauan kinematika gerak maka setiap benda memiliki sifat lembam yaitu sifat mempertahankan keadaan geraknya. Benda yang diam akan selalu diam dan benda yang bergerak lurus dengan kecepatan tertentu akan mempertahankan keadaan gerak lurus dengan kecepatan yang dimilikinya. Hukum fisika ini dikenal sebagai hukum pertama Newton. Sifat kelembaman ini dibawa oleh besaran massa. Semakin besar massa suatu benda maka semakin tinggi pula sifat kelembamannya yang berarti semakin sulit diubah keadaan geraknya.

Demikian pula yang terjadi pada dump truck yang melaju dengan kecepatan tinggi yang menyalip mobil boks namun pada saat menyalip mobil boks, sopir dump truck melihat bahwa dari arah yang berlawanan terdapat minibus tengah melaju dengan kecepatan yang tinggi. Walaupun dump truck dan minibus melakukan pengereman secara total, namun tidak dapat membuat kedua kendaraan berhenti secara total melainkan tetap bergeser sejauh jarak tertentu.

Kendaraan berat sejenis bus dan dump truck jika melakukan pengereman total secara mendadak memiliki perlambatan $3,5 \mathrm{~m} / \mathrm{s}^{2}$ sebagaimana informasi yang diperoleh dari kepolisian. Angka tersebut diperoleh dengan asumsi mendekati ideal, yaitu kondisi ban optimal dan jalan tak berminyak maupun berpasir. Jika kondisi ban dan jalan tidak ideal ditambah laju kendaraan melebihi asumsi, maka jarak dump truck dan minibus berhenti setelah pengereman total pertama kali dilakukan akan semakin jauh.

Pengereman secara total yang dilakukan pada kendaraan berat yang tengah melaju dengan kecepatan tinggi sangat berbahaya karena dapat menimbulkan momen gaya atau momen putar yang akan memutar-mutar kendaraan berat tersebut bahkan dapat menjungkirbalikkan kendaraan berat tersebut. Pada peristiwa tersebut dapat dipastikan bahwa sopir dump truck tidak mengerem secara total ketika dump truck menyalip mobil boks yang kemudian dari arah berlawanan terdapat minibus yang tengah melaju dengan kencang. Tabel I berikut menjelaskan mengenai spesifikasi kendaraan yang terlibat kecelakaan dalam jalur blackspot di jalan raya Trisnogambar, Bangsalsari, Jember.

Tabel 1. Data Spesifikasi Kendaraan

\begin{tabular}{lll}
\hline Jenis Kendaraan & $\begin{array}{l}\text { Kecepatan } \\
\text { Maksimum }\end{array}$ & Berat Kosong \\
\hline Minibus & $\mathrm{I} 80 \mathrm{~km} / \mathrm{jam}$ & $\mathrm{I} .085 \mathrm{~kg}$ \\
Dump Truck & $\mathrm{I} 03 \mathrm{~km} / \mathrm{jam}$ & $2.355 \mathrm{~kg}$ \\
Mobil Box & $\mathrm{I} 26 \mathrm{~km} / \mathrm{jam}$ & $2.081 \mathrm{~kg}$ \\
\hline
\end{tabular}

Kecepatan maksimum yang dapat dicapai oleh dump truck adalah $103 \mathrm{~km} /$ jam dengan daya tanjak $(\tan \phi)=$ 39,6 dengan berat kosong $2.355 \mathrm{~kg}$. Jika diasumsikan 
dump truck bergerak dengan kecepatan $40 \mathrm{~km} / \mathrm{jam}$ dan melaju beriringan dengan mobil boks, sehingga dapat dipastikan mobil boks memiliki kecepatan yang sama dengan dump truck. Ketika hendak menyalip mobil boks, maka dump truck harus menambah kecepatannya agar dapat mendahului mobil boks sehingga kecepatan dump truck ketika menyalip diasumsikan menjadi $50 \mathrm{~km} / \mathrm{jam}$. Asumsi nilai kecepatan kendaraan yang terlibat kecelakaan pada jalur blackspot di jalan raya Trisnogambar kecamatan Bangsalsari kabupaten Jember didasarkan dari data hasil pengamatan langsung di lapangan.

Pada saat yang bersamaan dari arah yang berlawanan terdapat minibus yang melaju dengan kecepatan tinggi, diasumsikan kecepatannya adalah $60 \mathrm{~km} / \mathrm{jam}$. Kecepatan maksimum yang dapat dicapai oleh minibus sejenis ini adalah $180 \mathrm{~km} / \mathrm{jam}$ akan tetapi asumsi didasarkan oleh observasi lapangan dimana mobil sejenis minibus melaju di jalan raya Trisnogambar dengan kecepatan berkisar 60 $\mathrm{km} /$ jam hingga $90 \mathrm{~km} / \mathrm{jam}$. Jika minibus melaju dengan kecepatan $60 \mathrm{~km} / \mathrm{jam}$ dan dump truck melaju dengan kecepatan $50 \mathrm{~km} / \mathrm{jam}$ setelah menyalip mobil boks, berapakah jarak yang terukur setelah minibus dan dump truck melakukan pengereman dengan nilai perlambatan maksimal? Kemudian berapa jarak yang diperlukan minibus untuk menghindari terjadinya kecelakaan jika dump truck dan minibus berjalan dengan nilai kecepatan maksimal?

Untuk mengetahui jawaban dari beberapa pertanyaan diatas maka dilakukan simulasi dengan besaran-besaran dinamis yang diperoleh dalam observasi, simulasi tersebut dibagi menjadi 3 kasus dimana kasus I adalah analisis terjadinya kecelakaan kemudian kasus 2 dan kasus 3 adalah analisis dari besaran-besaran dinamis yang memiliki potensi besar sebagai penyebab terjadinya kecelakaan. Kasus 2 dan kasus 3 merupakan uraian analisis matematis agar terhindar dari kecelakaan dengan memperhatikan besaran dinamis pada kasus I :

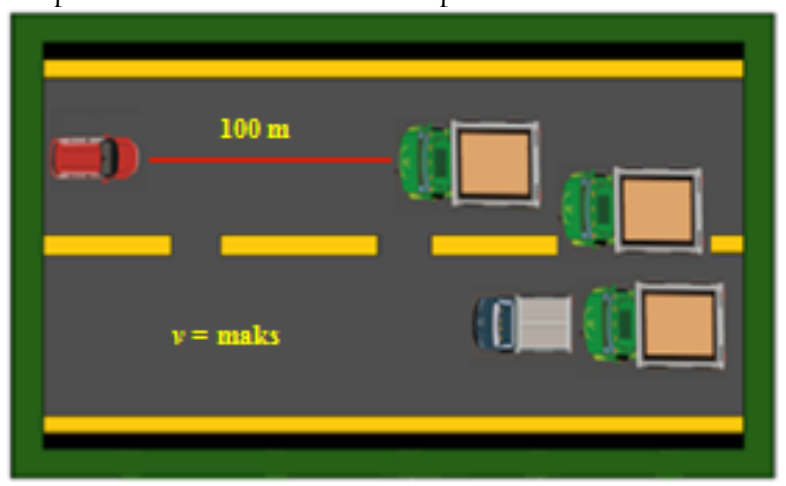

(a)

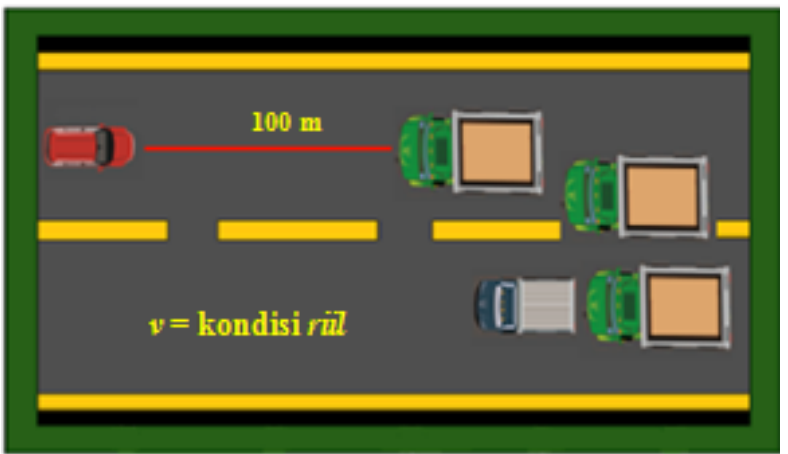

(b)

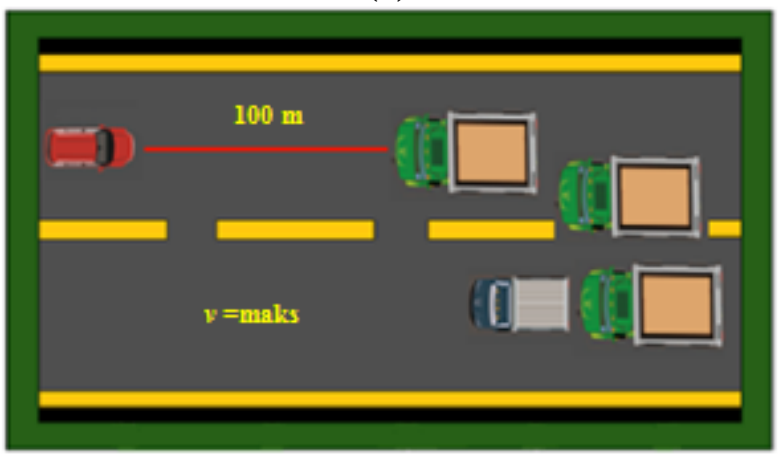

(c)

Gambar 2. Kondisi kendaraan untuk beberapa kasus; (a) kecepatan kendaraan maksimal dengan jarak $100 \mathrm{~m}$ (sesuai kondisi riii); (b) kecepatan kendaraan sesuai kondisi riil dengan jarak 100 m; (c) kecepatan kendaraan maksimal dengan jarak aman (tidak terjadi kecelakaan).

\section{Kasus 1}

Nilai kecepatan masing-masing kendaraan adalah maksimal (nilai maksimal dari data hasil observasi) dengan jarak kedua kendaraan sebelum pengereman adalah IOO meter. Dapatkah kendaraan tersebut terhindar dari kecelakaan?

Diketahui :

\begin{tabular}{ll}
\hline \multicolumn{1}{c}{ Dum Truck } & Minibus \\
\hline$v_{0}=60 \mathrm{~km} / \mathrm{jam}=16.67 \mathrm{~m} / \mathrm{s}$ & $v_{0}=90 \mathrm{~km} / \mathrm{jam}=25 \mathrm{~m} / \mathrm{s}$ \\
$a=3.5 \mathrm{~m} / \mathrm{s}^{2}$ & $a=3.5 \mathrm{~m} / \mathrm{s}^{2}$ \\
$v=v_{0}-a t$ & $v=v_{0}-a t$ \\
\hline
\end{tabular}




\begin{tabular}{ll}
\hline \multicolumn{1}{c}{ Dum Truck } & \multicolumn{1}{c}{ Minibus } \\
\hline $0=16.67 \mathrm{~m} / \mathrm{s}-3.5 \mathrm{t}$ & $0=25 \mathrm{~m} / \mathrm{s}-3.5 \mathrm{t}$ \\
$3.5 \mathrm{t}=16,67 \mathrm{~s}$ & $3.5 \mathrm{t}=25 \mathrm{~s}$ \\
$t=4.67$ & $t=7.14$
\end{tabular}

$$
\begin{aligned}
& s=v_{0} t-\frac{1}{2} a t^{2} \\
& =16.67(5.76)-\frac{1}{2}(3.5)(4,76)^{2} \\
& =79.34-39.65 \\
& =39.6 \mathrm{~m}
\end{aligned}
$$

Jika jarak kedua kendaraan sebelum pengereman adalah IOO meter, jarak minibus setelah melakukan pengereman adalah 89,2 meter dan jarak dump truck setelah melakukan pengereman adalah 39,6 meter maka dapat dipastikan kedua kendaraan mengalami kecelakaan. Hal ini dikarenakan jumlah total dari jarak kedua kendaraan tersebut melebihi angka mula-mula jarak yaitu 100 meter. Untuk mengetahui pada titik mana kedua kendaraan bertabrakan, maka dilakukan analisis sebagai berikut:

$$
\begin{aligned}
& S_{A}=v_{0 A} t_{A}-\frac{1}{2} a t_{A}{ }^{2} \\
& S_{B}=v_{0 B} t_{B}-\frac{1}{2} a t_{B}{ }^{2}
\end{aligned}
$$

Persamaan (I) untuk dumptruck dan persamaan (2) untuk minibus, karena bertabrakan sehingga $t_{A}=t_{B}=t$, maka persamaan (I) dan (2) menjadi

$$
\begin{aligned}
& S_{A}=v_{0 A} t-\frac{1}{2} a t^{2} \\
& S_{B}=v_{0 B} t-\frac{1}{2} a t^{2}
\end{aligned}
$$

Karena $S_{A}+S_{B}=100$ maka,

$$
S_{A}=100-S_{B}
$$

Sehingga substitusikan persamaan (3) dengan persamaan (5) menjadi

$$
100-S_{B}=v_{0 A}-\frac{1}{2} a t^{2}
$$

Kemudian persamaan (5) dan persamaan (4) di eliminasi dengan menjumlahkan keduanya agar memperoleh besaran waktu,

$$
\begin{aligned}
& s=v_{0} t-\frac{1}{2} a t^{2} \\
& =25(7.14)-\frac{1}{2}(3.5)(7.14)^{2} \\
& =178.5-89.2 \mathrm{I} \\
& =89.2 \mathrm{~m}
\end{aligned}
$$

$$
\begin{gathered}
100-S_{B}=v_{0 A}-\frac{1}{2} a t^{2} \\
S_{B}=v_{0 B} t-\frac{1}{2} a t^{2} \\
100=v_{0 A} t+v_{0 B} t-a t^{2} \\
100-v_{0 A} t-v_{0 B} t+a t^{2}=0 \\
a t^{2}-\left(v_{0 A} t+v_{0 B} t\right)+100=0 \\
(3.5) t^{2}-(16.67 t-25 t)+100=0 \\
(3.5) t^{2}-(41.67 t)+100=0
\end{gathered}
$$

Karena diperoleh persamaan kuadrat maka digunakan penyelesaian dengan rumus abc, sehingga

$$
\begin{aligned}
& t_{1,2}=\frac{-b \pm \sqrt{b^{2}-4 a c}}{2 a} \\
& t_{1,2}=\frac{-(-41.67) \pm \sqrt{(-41.67)^{2}-4(3.5)(100)}}{2(3.5)} \\
& t_{1,2}=\frac{41.67 \pm \sqrt{336.3889}}{7} \\
& t_{1,2}=\frac{41.67 \pm \sqrt{336.3889}}{7} \\
& t_{1,2}=\frac{41.67 \pm 18.34}{7} \\
& t_{1}=\frac{41.67+18.34}{7}=8.5728 \text { sekon } \\
& t_{2}=\frac{41.67-18.34}{7}=3.332 \text { sekon }
\end{aligned}
$$

Karena nilai $t_{2}$ lebih kecil dari nilai $t_{1}$, maka $t_{2}$-lah yang digunakan untuk mensubstitusikan persamaan (I) 
$S_{A}=v_{0 A} t-\frac{1}{2} a t^{2}$

$S_{A}=(16.67)(3.332)-\frac{1}{2}(3.5)(3.332)^{2}$

$S_{A}=33.54-19.42$

$S_{A}=36.12$ meter

Substitusikan persamaan (2)

$S_{B}=v_{0 B} t-\frac{1}{2} a t^{2}$

$S_{B}=(25)(3.332)-\frac{1}{2}(3.5)(3.332)^{2}$

$S_{B}=83.3-19.42$

$S_{B}=63.88$ meter
Sehingga nilai $S_{A}$ atau jarak yang ditempuh dumptruck ketika bertabrakan adalah 36,13 meter, sedangkan nilai $S_{B}$ atau jarak yang ditepuh minibus ketika bertabrakan adalah 63,88 meter dengan waktu yang terurukur ketika kecelakaan adalah 3,332 detik.

\section{Kasus 2}

Nilai kecepatan masing-masing kendaraan adalah sesuai kondisi riil atau sesuai dengan rata-rata kecepatan kendaraan yang melintas dan jarak kedua kendaraan sebelum pengereman adalah 100 meter. Dapatkah kendaraan tersebut terhindar dari kecelakaan?

\begin{tabular}{|c|c|}
\hline Dump Truck & Minibus \\
\hline$v_{0}=50 \mathrm{~km} / \mathrm{jam}=13,8 \mathrm{~m} / \mathrm{s}$ & $v_{0}=60 \mathrm{~km} / \mathrm{jam}=16,67 \mathrm{~m} / \mathrm{s}$ \\
\hline$a=3,5 \mathrm{~m} / \mathrm{s}^{2}$ & $a=3,5 \mathrm{~m} / \mathrm{s}^{2}$ \\
\hline$v_{t}=v_{0}-a t$ & $v_{t}=v_{0}-a t$ \\
\hline $0=13,8 \mathrm{~m} / \mathrm{s}-3,5 t$ & $0=16,67 \mathrm{~m} / \mathrm{s}-3,5 t$ \\
\hline $3,5 t=13,8$ & $3,5 t=16,67$ \\
\hline$t=3,9 \mathrm{~s}$ & $t=4,76 \mathrm{~s}$ \\
\hline$s=v_{0} t=\frac{1}{2} a t^{2}$ & $s=v_{0} t=\frac{1}{2} a t^{2}$ \\
\hline$=13,8(3,9)-\frac{1}{2}(3,5)(3,9)^{2}$ & $=16,67(4,76)-\frac{1}{2}(3,5)(4,76)^{2}$ \\
\hline$=53,82-26,61$ & $=79,34-39,65$ \\
\hline$=27,2 \mathrm{~m}$ & $=39,6 \mathrm{~m}$ \\
\hline
\end{tabular}

Jika jarak kedua kendaraan sebelum pengereman adalah IOO meter, jarak minibus setelah melakukan pengereman adalah 39,6 meter dan jarak dump truck setelah melakukan pengereman adalah 27,2 meter maka dapat dipastikan kedua kendaraan tidak mengalami kecelakaan.

\section{Kasus 3}

Nilai kecepatan masing-masing kendaraan adalah maksimal dengan jarak kedua kendaraan sebelum pengereman belum diketahui. Untuk itu berapa jarak yang aman agar kendaraan tersebut terhindar dari kecelakaan?

\begin{tabular}{ll}
\hline Dump Truck & Minibus \\
\hline$v_{0}=60 \mathrm{~km} / \mathrm{jam}=16,67 \mathrm{~m} / \mathrm{s}$ & $v_{0}=90 \mathrm{~km} / \mathrm{jam}=90 \mathrm{~m} / \mathrm{s}$ \\
$a=3,5 \mathrm{~m} / \mathrm{s}^{2}$ & $a=3,5 \mathrm{~m} / \mathrm{s}^{2}$ \\
$v_{t}=v_{0}-a t$ & $v_{t}=v_{0}-a t$ \\
$0=16,67 \mathrm{~m} / \mathrm{s}-3,5 t$ & $0=25 \mathrm{~m} / \mathrm{s}-3,5 t$ \\
$3,5 t=16,67$ & $3,5 t=25$ \\
$t=4,76 \mathrm{~s}$ & $t=7,14 \mathrm{~s}$ \\
\end{tabular}




\begin{tabular}{ll}
\hline Dump Truck & Minibus \\
\hline$s=v_{0} t=\frac{1}{2} a t^{2}$ & $s=v_{0} t=\frac{1}{2} a t^{2}$ \\
$=16,67(4,76)-\frac{1}{2}(3,5)(4,76)^{2}$ & $=25(7,14)-\frac{1}{2}(3,5)(7,14)^{2}$ \\
$=79,34-39,65$ & $=178,5-89,21$ \\
$=39,6$ meter & $=89,2$ meter \\
\hline
\end{tabular}

Analisis untuk kecepatan maksimal telah diuraikan pada kasus I, dimana dengan jarak I00 meter sebelum pengereman kedua kendaraan tersebut dipastikan mengalami kecelakaan. Jika jarak kedua kendaraan sebelum pengereman lebih dari $\mathrm{IOO}$ meter, jarak minibus setelah melakukan pengereman adalah 89,2 meter dan jarak dump truck setelah melakukan pengereman adalah 39,6 meter maka jarak yang aman adalah minimal I50 meter untuk menghindari kedua kendaraan mengalami kecelakaan.

Analisis untuk kecepatan maksimal yang telah diuraikan pada kasus I, dimana dengan jarak I00 meter sebelum pengereman kedua kendaraan tersebut dipastikan mengalami kecelakaan. Jika jarak kedua kendaraan sebelum pengereman lebih dari $\mathrm{IOO}$ meter, jarak minibus setelah melakukan pengereman adalah 89,2 meter dan jarak dump truck setelah melakukan pengereman adalah 39,6 meter maka jarak yang aman adalah minimal I50 meter untuk menghindari kedua kendaraan mengalami kecelakaan.

Data-data yang telah di peroleh kemudian dianalisis berdasarkan materi kinematika gerak di SMA, selanjutnya hasil tersebut akan dikembangkan menjadi rancangan sumber belajar. Rancangan sumber belajar itu sendiri akan dibuat menjadi rancangan sumber belajar yang benarbenar kontekstual atau kajian real life. Pendekatan kontekstual mengajak siswa mengaitkan materi yang diajarkan dengan situasi dunia nyata dan mendorong siswa membuat hubungan antara pengetahuan yang dimiliki dengan penerapan dalam kehidupan sehari-hari siswa sehingga siswa akan mengalami pembelajaran yang bermakna[6]. Rancangan sumber belajar yang dibuat tidak hanya menekankan pada penguasaan materi yang akan diajarkan saja melainkan juga memberikan penekanan pada kemampuan siswa untuk berpikir kritis, menganalisa permasalahan, dan mampu menyampaikan pendapat dari setiap materi yang berkaitan dengan situasi yang nyata. Sehingga bentuk dari rancangan sumber belajar ini berupa materi, fenomena sehari-hari (kecelakaan pada jalur blackspot), contoh soal, dan latihan soal yang mampu mengajak siswa untuk berpikir kritis.

Konsep fisika yang dijelaskan melalui peristiwa kontekstual dapat membantu siswa memahami materi dengan mudah. Karena siswa mampu menghubungkan materi pembelajaran dengan konteks kehidupan sehari- hari untuk menemukan makna. Guru dapat menentukan konsep fisika untuk diajarkan kepada siswa dan bagaimana mengajar siswa agar dapat memahami materi[7]. Rancangan sumber belajar ini dapat digunakan sebagai sumber referensi guru dalam mengajarkan konsep fisika kepada siswa khususnya materi mekanika gerak dan dapat dikembangkan lagi oleh guru atau peneliti lainnya untuk pembelajaran materi kinematika dan dinamika gerak di SMA dalam bentuk buku teks atau Lembar Kerja Siswa (LKS). Oleh karena itu rancangan sumber belajar ini dapat dijadikan referensi bagi guru untuk menjelaskan konsep fisika dengan menggunakan peristiwa kontekstual yang sangat dekat dengan siswa.

\section{Kesimpulan}

Berdasarkan hasil analisis kejadian kecelakaan dapat disimpulkan bahwa kejadian kecelakaan pada jalur blackspot dapat dianalisis secara kinematika gerak. Besaran dinamis yang diperoleh meliputi jarak, perpindahan, kecepatan, waktu, dan massa kendaraan. Hasil kajian kejadian kecelakaan di daerah blackspot dapat digunakan sebagai rancangan sumber belajar yang kontekstual. Selain itu juga dapat digunakan sebagai acuan bagi para pengendara yang melintas di daerah yang diteliti dalam memacu kendaraan, terutama dalam mempertimbangkan batas maksimum kecepatan kendaraan dan jarak maksimum yang ditempuh saat melakukan pengereman guna mengantisipasi terjadinya kecelakaan.

\section{Kepustakaan}

[I] Tebabal, A., dan G. Kahssay. 20II. The effect of student centered approach in improving students graphical interpretion skills and conceptual understanding of kinematical motion. Lat. Am. J. Phys. Educ. 5(2): 374-381.

[2] Narjikaew, P. 2013. Alternative Conception of Primary School Teacher of Science about Force and Motion. Procedia-Social and Behavioral Science. 88. I I-I4 Desember 2012. Elsevier Ltd: 250257.

[3] Yogantari, P. 20I5. Identifikasi kesulitan siswa dalam pembelajaran fisika. Prosiding Seminar Nasional Fisika dan Pembelajarannya 2015.29 Agustus 2015. PF-PP-7

[4] Satriawan, M. \& Rosmiati. 20I6. Pengembangan bahan ajar fisika berbasis kontekstual dengan mengintegrasikan kearifan lokal untuk meningkatkan pemahaman konsep fisika pada mahasiswa. 
Kajian kinematika gerak pada jalur lokasi kecelakaan berisiko tinggi (blackspot) sebagai sumber belajar fisika di SMA

Pendidikan Sains Pascasarjana Universitas Negeri Surabaya. 6(I): I2I2-I2I7

[5] Ornek, F., Robinson, W. R., dan Haugan, M. P. (2008). What makes physics difficult?. International Journal of Environmental \& Science Education. Vol. 3 No. I, pp. 30-34.

[6] M.S. Majid, 2016. Pembelajaran Fisika Dengan Pendekatan Kontekstual Melalui Metode Eksperimen Dan Demonstrasi Diskusi Pada Materi Kinematika Gerak Lurus. Jurnal Teknika STTKD, 3 (2): 92 - 106

[7] Supeno, M.Nur dan E.Susanti. 2015. Developing A Tectbook Based On Argumentation Skills To Facilitate Students In Physics Instruction. Proceeding International Conference: Trending Issues Of School Education In Advanced Countries And Indonesia. ISSN: 2443-2768 